\title{
Ananda Devi, Ève de ses décombres
}

\section{Alessandro Corio}

\section{(2) OpenEdition}

\section{Journals}

\section{Edizione digitale}

URL: http://journals.openedition.org/studifrancesi/28248

DOI: 10.4000/studifrancesi.28248

ISSN: 2427-5856

\section{Editore}

Rosenberg \& Sellier

\section{Edizione cartacea}

Data di pubblicazione: 31 décembre 2006

Paginazione: 651-652

ISSN: 0039-2944

\section{Notizia bibliografica digitale}

Alessandro Corio, « Ananda Devi, Ève de ses décombres », Studi Francesi [Online], 150 (L | III) | 2006,

online dal 30 novembre 2015, consultato il 08 novembre 2020. URL : http://journals.openedition.org/ studifrancesi/28248; DOI : https://doi.org/10.4000/studifrancesi.28248

\section{Questo documento è stato generato automaticamente il 8 novembre 2020.}

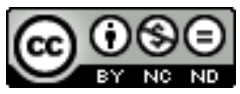

Studi Francesi è distribuita con Licenza Creative Commons Attribuzione - Non commerciale - Non opere derivate 4.0 Internazionale. 


\title{
Ananda Devi, Ève de ses décombres
}

\author{
Alessandro Corio
}

\section{NOTIZIA}

ANANDA DEVI, Ève de ses décombres, Paris, Gallimard, 2006, pp. 155.

1 Giunta ormai nell'olimpo editoriale con la pubblicazione nella collana principale della Gallimard (dopo essere passata inizialmente per piccole case editrici dell'Oceano Indiano e africane, poi per L'Harmattan e infine per la collana "Continents noirs" sempre di Gallimard), Ananda Devi conferma indubbiamente con quest'ultimo romanzo, dal titolo accattivante, le sue qualità di scrittrice. I personaggi di Ève de ses décombres sono le voci narranti di quattro adolescenti di un quartiere periferico di Port Louis, capitale dell'île Maurice. Il nome di questo quartiere, Troumaron, porta iscritto, nell'eco della figura dell'ésclave marron, la sua condanna e il suo destino: un destino di marginalità, di esclusione e di violenza, lo stesso dei suoi abitanti che, fin da bambini, consumano i loro corpi e i loro cuori nell'odore ristagnante dell'assenza di speranza: «Notre cité est notre royaume. Notre cité dans la cité, notre ville dans la ville. Port Louis a changé de figure, il lui est poussé des dents longues et des immeubles plus hauts que ses montagnes. Mais notre quartier, lui, n'a pas changé. C'est le dernier retranchement. Ici, on se construit une identité par défaut: celle des non-appartenants» (p. 17). Sad, Ève, Savita e Clélio incarnano il destino disperato di quei soggetti che la critica post-coloniale definirebbe "subalterni", coloro che vengono esclusi e schiacciati dagli impietosi meccanismi di una società che si sviluppa espandendo ed irradiando gli apparati sociali che riproducono la ricchezza ed il potere delle élites, rigettando ai margini quei corpi-rifiuti che non trovano spazio nelle articolazioni biopolitiche e produttive dominanti. Ananda Devi è capace di rappresentare questa realtà senza retorica e senza l'ingenuità di un pretenzioso realismo che rischierebbe di abusare dell'autorità consolidata della Scrittura, rendendo trasparente il soggetto autoriale nella rappresentazione/messa in scena dell'altro. Al contrario, la sua scrittura sceglie la via più consapevole e più ardua della indagine introspettiva nelle macerie dell'animo, della messa a nudo dell'altro indicibile della parola, sui cui margini la parola letteraria 
cerca il contatto con la coscienza dell'altro, in bilico tra forza e delicatezza dell'espressione, restituendogli una voce. Lo fa attraverso uno stile prevalentemente paratattico, frammentato, percorso da ripetizioni, fraseggi idiomatici ricalcanti l'espressione orale ed inserti in creolo: uno stile che la sorregge pienamente costituendone il motivo principale di fascino e di efficacia. Le figure del "rifiutomaceria" e del "corpo defunto" ritornano in continuazione nella rappresentazione dell'interiorità violenta e sofferente dei personaggi e l'esile vicenda è narrata quasi completamente attraverso il punto di vista soggettivo dei quattro protagonisti, attraverso l'intrecciarsi, con uno schema molto semplice, dei loro percorsi individuali, risucchiati da una forza più grande della loro lotta, che li circonda e li cattura, trascinandoli, tra tristezza e crudeltà, verso una tragedia inevitabile.

Eppure, sebbene non sia possibile salvezza alcuna in questo inferno dei viventi - dove si muore ogni giorno proprio come la protagonista Ève, che sceglie di barattare la sua sopravvivenza per mezzo di un corpo che le è divenuto estraneo, fino ad esibire i segni del suo decomporsi - proprio nelle piaghe doloranti di un'anima e di un corpo che lottano attraverso la rabbia, la scrittura di sé in un orizzonte intimo e lontano, la violenza della ribellione e della vendetta che nasconde una capacità immensa di compassione, resiste un impulso significante, non fosse altro che la consapevolezza profonda di non appartenere a quest'inferno: «Rien de tout cela n'est toi. [...] Tu n'est pas d'ici, te dis-tu. Tu le diras jusqu'à la fin des choses». (p. 53)

Ritroviamo quindi due temi centrali della produzione narrativa di Ananda Devi, tra loro strettamente collegati: quello della chiusura-prigionia ("enfermement") causata dall'esclusione dall'ambiente sociale circostante e quello speculare della riappropriazione di sé attraverso la scrittura e la dimensione fisico-corporale, allegorie parallele di una re-iscrizione del proprio sé come soggetto di un'agentività perturbativa nei confronti degli ordinamenti sociali. I due personaggi che rappresentano questa tematica ancipite e questa pulsione votata al fallimento sono Sad e Ève: il primo esprime la forza di un amore impossibile che lo condurrà ad un gesto finale di sacrificio e che egli può esprimere soltanto scrivendo sui muri della sua stanza la materia pulsante di una voce presa in prestito da un altro adolescente ribelle in cerca dell'assoluto attraverso la parola: Arthur Rimbaud. Ma, agli occhi di Ève, la sua passione di costruire un sogno alternativo dentro di sé risulta una derisoria ed inutile illusione di salvezza in un giardino di macerie e di disperazione. La sua scelta è all'opposto quella dell'autodistruzione di sé, o meglio, di quell'apparenza esterna del proprio corpo desiderato e violato dalla "potenza sovrana" dell'uomo, per essere infine rigettato tra i rifiuti del proprio destino di decomposizione: «Tout masquer et marcher sur des braises, ne rien laisser paraitre de soi. Je les laisse croire que je suis à prendre et à laisser. Je les laisse croire que je ne suis rien d'autre qu'un corps, ce corps là qui, quand ils le déshabillent, les fait frémir. Un corps si frêle, si maigre, si cassable; un corps à chérir ou à détruire; c'est ce qu'ils s'appliquent à faire» (p. 61). L'unica via di fuga dalle costrizioni violente che la assediano e da cui si lascia possedere è l'amore che la lega a Savita, incarnazione del sentimento di compassione e di fraternità, condannata anche lei a scomparire a causa della fragilità della sua intima bellezza. Diametralmente opposto, in quest'incrocio di voci e di destini, è il personaggio di Clélio, personificazione della collera e della violenza che sono per lui l'unico linguaggio possibile attraverso cui esprimere il risentimento e la ribellione verso tutto ciò che lo circonda, condannandolo ad essere il capro espiatorio di una violenza più nascosta e sottile, che segna la sua e la 
loro condanna fin dalla nascita: « [...] des siècles à être ennemis, esclaves, coolies, c'est une lourde histoire, n'empêche, et à chaque occasion elle refait surface, des siècles que ça dure et c'est pas près de finir, croyez moi, [...] nous les enfants de Troumaron, nous sommes d'une seule communauté, qui est universelle, celle des pauvres et des paumés et là, croyez-moi, c'est la seule identité qui compte» (p. 104). Alle voci dei quattro protagonisti che si alternano lungo il racconto, fa da contrappunto un punto di vista esterno, marcato dal corsivo, che attraversa i personaggi e descrive alla seconda persona, esprimendo in tal modo una prossimità emotiva, i moti più profondi del loro animo, cucendoli assieme come un "ago e filo" ed intensificando ulteriormente il tono lirico di questa prosa poetica.

4 Alla dimensione individuale si affianca quella collettiva, di tutt'altra natura, della banda, che funziona attraverso logiche proprie e che trascina l'individuo e la sua coscienza in un'animalità cieca e vendicativa, che riproduce continuamente la violenza stessa che la genera. Non c'è salvezza qui, solo il continuo ripetersi e riprodursi della logica primitiva del branco, che da l'illusione di continuare a vivere, anche per un solo istante, «vivre comme une note tirée d'une guitare, discordante, mais perçue de loin. Ne pas disparaitre. Ne pas renoncer à être» (p. 127). Sembra non esserci salvezza né speranza in questo mondo di macerie che attraversano l'anima, il corpo e le relazioni sociali. Nel finale, sebbene esso sia marcato da un gesto di dolcezza, il sipario cala su un "paesaggio di rovine" e l'isola tropicale che si veste di un cielo blu e di un mare cristallino per attirare le carte di credito dei ricchi turisti, padroni indiscussi di quest'ordine, nasconde, nei suoi recessi ignorati dai loro sguardi opachi, un dolore sordo che continua a nutrirsi solamente di se stesso. 